\title{
A COMMUNITY SURVEY OF CHILD CARE ISSUES IN CANADIAN SHIFT WORKERS: EVIDENCE FOR BARRIERS AND OPPORTUNITIES
}

\author{
Phoebe Scotland, The Elk Valley Child Care \\ Advisory Initiative, and The Elkford Women's Task Force
}

\begin{abstract}
Child care availability and affordability are common concerns throughout many communities in Canada. Furthermore, there are specific child care issues affecting families that include shift workers. A formal initiative was developed in the Elk Valley, British Columbia, following identification of child care as a major concern of residents, and in 2015 a survey was conducted with the aim of understanding child care issues as they relate to employment. The intent was to investigate barriers and opportunities, and to develop both short- and long-term mitigation strategies. The survey queried the perspectives of 302 respondents, including parents, guardians, and other caregivers, as well as child care providers, employers, and other interested community members. The results confirmed that there are barriers to availability and affordability of child care and allowed for recommendations regarding mitigation strategies. Furthermore, respondents indicated that municipal governments, the provincial government, local employers, child care providers, families, and other community organizations are responsible for working together to develop solutions to the child care issues. The results of this community-based survey are applicable to other communities across Canada and internationally, and provide insight into child care issues that impact the workforce.
\end{abstract}

Keywords: child care, shift work, parents, dual-income, employer, employee, early childhood education, workforce

Phoebe Scotland, M.A. (the corresponding author) is an instructor in psychology at the College of the Rockies, 2700 College Way, Cranbrook, BC, V1C 5L7.

Email: phoebe.scotland@gmail.com

The Elk Valley Child Care Advisory Initiative was formed to provide the Teck Coal Communities of Interest (COI) Advisory Initiative with data to be used toward the mandate of fostering dialogue and developing solutions regarding child care issues, sector-specific challenges, and shortages of child care options in the Elk Valley. 116 Centennial Street, PO Box 1777, Sparwood, BC, V0B 2G0. Email: Sharon.Strom@teck.com

The Elkford Women's Task Force is a charitable non-profit organization formed in 1992 to address social needs impacting community members, particularly women. P.O. Box 742, Elkford, BC, V0B 1H0. Email: ewtf@telus.net 
High-quality child care is an essential component of a healthy society. Child care that meets a population's needs promotes healthy child development, increases participation of women in the workforce, provides economic advantages to families and to society overall, and reduces workplace absenteeism by employed parents (Invanova, 2015). Despite the benefits of high-quality child care, there is widespread recognition that child care, particularly care that is provided by certified early childhood educators (ECEs), is not meeting the needs of British Columbia (BC) families (Invanova, 2015). Most child care arrangements follow typical daytime work schedules, which produces additional challenges for shift workers who rely on paid child care. While some dual-parent families find that shift work can contribute to successful child care solutions, shift work is associated with numerous challenges related to family scheduling (Williams, 2008). Approximately 20\% of the Canadian workforce is employed in some form of shift work (Statistics Canada, 2011g), therefore scheduling that incorporates shift work is common in Canadian families. Occupations where shift work is common include manufacturing, some trades, food and service industries, and emergency responders.

The present study originated from a formal initiative developed in the Elk Valley, BC, Canada, with the aim of understanding child care issues as they relate to employment. This grassroots project originated from identification of child care as a major concern of area residents, who sought both short- and long-term mitigation strategies. Our survey data describe child care use, needs, barriers, and opportunities in the Elk Valley. Although the data are specific to the three communities studied, the findings are relevant to other communities facing similar child care issues. Comparable communities exist across BC, across Canada, and internationally. The need for flexible child care in Canada has been formally reported on since at least 1989 (Friendly, Cleveland, \& Willis, 1994), yet many of the same issues remain. The present findings and resulting recommendations propose strategies at several levels, including individuals and families, community support, broader community development, and governmental policy.

In BC, there are two major categories of child care: licensed and unlicensed (sometimes also referred to as licence not required, or LNR, care). Whether a child care provider must be licensed or not is determined by factors such as the number of children in care at a given time and the duration of care. The BC Community Care and Assisted Living Act applies to all licensed child care programs, and sets requirements for "staffing qualifications, staff to child ratio, space and equipment, and program standards" (Government of British Columbia, 2009, p. 5). The Community Care and Assisted Living Act also outlines approved Early Childhood Educator (ECE) programs for obtaining professional credentials and first aid requirements for child care providers. Types of child care are outlined in the Parents' Guide to Selecting and Monitoring Child Care in $B C$, published by the Government of British Columbia (2009), and are described below. This full description is relevant to the present study because the type of care and associated staffing requirements are components of fully understanding child care barriers and opportunities.

Group child care is a type of licensed care that can include infant and toddler care for children from birth to 36 months of age, and preschool care for children ages 30 months to Grade 1. 
Infant/toddler group child care is required to have at least one licensed Infant/Toddler ECE, one ECE, and one ECE Assistant per 12 children. Group child care for children over 30 months of age is required to have at least one ECE and two ECE Assistants for groups of up to 25 children. School-age group child care is a type of licensed care for children who attend school and require care outside of school hours. These programs require one "responsible adult" for every 10 children in kindergarten or Grade 1 (maximum group size of 20 children), and one "responsible adult" for every 15 children in Grades 2 and higher (maximum group size of 25 children). "Responsible adults” are people aged 19 years and older who have completed 20 hours of training, completed first aid certification, and passed a criminal record check. Preschool programs also operate for children who are at least 30 months old and have not begun Grade 1. Children attend preschool programs for a maximum of 4 hours per day, in groups of 20 or fewer children, and are staffed by at least one ECE for every 10 children, or one ECE and one ECE assistant for a group of 20 children.

Family child care, another type of licensed care, operates out of the care provider's own home rather than a child care centre. This type of care can accommodate children from birth to 12 years of age, and the care provider is a "responsible adult" who is licensed to care for up to seven children of varying ages. There are specific regulations regarding the age combinations that are permitted in this type of child care arrangement. Also, any family members or others over the age of 12 who live in the home must pass a criminal record check. In-home multi-age child care is provided in the care provider's home, but in this case, the care provider is an ECE licensed to practice in $\mathrm{BC}$, and can care for up to eight children at once. There are regulations regarding the age combinations of the children, and other requirements such as a criminal record check for people in the home over age 12. Multi-age centre-based care is also licensed, and is provided by an ECE, with a maximum of eight children per ECE at a given time.

Unlicensed or LNR child care is permitted for situations where a provider cares for a maximum of two children or one sibling group at a given time, who are not related to the provider by blood or marriage. Care providers are encouraged to register with their local Child Care Resources and Referral (CCRR) program, but this is not an obligation. LNR care refers to those providers who are not registered, whereas registered LNR (RLNR) care refers to those providers who have met requirements including passing a criminal record check, character reference checks, a home safety assessment, a physician's report on their physical and emotional capacity to care for children, first aid training, and participation in training related to child care. In child's own home is a third type of unlicensed child care, and refers to child care that is provided by a nanny, babysitter, or au pair. In this situation, parents are responsible for making Employment Insurance and Canada Pension Plan payments, as well as meeting other obligations of employers.

ECEs complete several components of training in order to receive their professional credentials. ECEs are licensed through the Early Childhood Educator Registry of BC, and have completed an approved ECE training program, work experience requirements, character and work reference checks, and passed a criminal record check. The ECE licence to practise must be renewed 
every 5 years, and requires 400 hours of related work experience, references, and demonstrated completion of 40 professional development training hours. Approved ECE training programs take approximately 1 year to complete, with an additional year of training required for infant/toddler or special needs designations.

Certified ECE Assistants must have completed at least one ECE class in child growth and development, health, safety and nutrition, or child guidance. They must also have related work experience, complete character and work reference checks, and pass a criminal record check. Certification is administered through the Early Childhood Educator Registry of BC, and expires every 5 years. The renewal requirements include 400 hours of related work experience, reference checks, and completion of an additional post-secondary class with relevant content. There are provincial differences in licensing standards to practice as an ECE, and training is not necessarily accepted between provinces.

\section{The Present Study}

We aimed to document barriers and opportunities regarding child care, in three communities composed primarily of shift workers. Data-based recommendations were developed, which suggest mitigation strategies for the identified child care concerns. The data are discussed in the context of child care throughout Canada and internationally.

Due to a perceived child care crisis in Fernie, Sparwood, and Elkford, the Elk Valley Child Care Advisory Initiative (EVCCAI) was established in January 2014, and members determined that quantifiable data-based findings on child care barriers and opportunities would be needed in order to propose recommendations to community organizations, industry, and various levels of government. A collaboration was formed with the Elkford Women's Task Force (EWTF), an Elk Valley non-profit society that operates local social programs. Together, the EVCCAI and the EWTF obtained funding from the Columbia Basin Trust in order to conduct the Elk Valley Child Care Barriers and Opportunities Survey. The survey aimed to:

1. Increase understanding of concerns related to affordability and availability of child care in the Elk Valley.

2. Increase understanding of whether child care issues create barriers to employment in the Elk Valley.

3. Document opportunities for short- and long-term mitigation strategies.

4. Develop data-based recommendations for solutions that are specific to each of the three largest communities in the Elk Valley.

The survey findings were presented publicly in each community, at general community presentations, and to local city councils. They have also been presented online at www.ekkids.ca. 


\section{Communities Surveyed}

The survey was conducted in the communities of Fernie, Sparwood, and Elkford. Variables related to child care in each community appear in Table 1.

Table 1 Community Characteristics

\begin{tabular}{lccc}
\hline \multicolumn{1}{c}{ Characteristic } & Fernie & Sparwood & Elkford \\
\hline Population* & 4,448 & 3,667 & 2,518 \\
Ages 0-4 years* & 240 & 220 & 185 \\
Ages 5-9 years* & 215 & 225 & 180 \\
Licensed group care spaces & 12 & 8 & 0 \\
Children waitlisted for & 40 & 20 & $\mathrm{n} / \mathrm{a}$ \\
licensed group care & 48 & 8 & $\mathrm{n} / \mathrm{a}$ \\
Preschool spaces & $\$ 940 / \$ 740$ & $\$ 1166 / \$ 895$ & $\mathrm{n} / \mathrm{a}$ \\
Cost of licensed group care & per month & per month & \\
(infant toddler/preschool age) & 8:15 a.m. to 4:45 p.m. & $6: 15$ a.m. to 5:30 p.m. \\
Hours of licensed care & Monday-Friday & Monday-Friday & $\mathrm{n} / \mathrm{a}$ \\
Licensed family care spaces & 7 & 7 & $\mathrm{no}$ \\
StrongStart program & yes & yes & \\
\hline
\end{tabular}

${ }^{*}$ Census, Statistics Canada, 2011a, 2011b, 2011c

As indicated in Table 1, both Fernie and Sparwood have StrongStart programs, which provide opportunities for supported child development in these communities, but do not meet child care needs, as parents must attend with their children. A pilot project called Healthy Start is operated in Elkford on Saturdays by the EWTF; the program focuses on fitness, healthy eating, and other issues related to child development. However, the Healthy Start program is also not a child care option, as it requires parent participation. Furthermore, the limited opportunities for after school care in Fernie and Sparwood do not meet community needs. Elkford residents report that the Elk Valley Garage Sale Facebook group is a common place to find child care providers, but many residents have expressed safety concerns over this option.

In addition to the data presented above, it is relevant to note the most common industries reported in each community, according to the Statistics Canada 2011 National Household Survey (NHS), which used the North American Industry Classification System (NAICS) 2007. In Fernie, these were (a) mining, quarrying, and oil and gas extraction (570 of 2,720 people participating in the labour force); (b) accommodation and food services (350 people); and (c) health care and social assistance (340 people; Statistics Canada, 2011e). In Sparwood, the most common industries were 
(a) mining, quarrying, and oil and gas extraction (665 of 2,075 people in the labour force); (b) health care and social assistance (170 people); and (c) wholesale trade (140 people) and retail trade (140 people; Statistics Canada, 2011f). The primary NAICS-classified industries in Elkford were (a) mining, quarrying, and oil and gas extraction (705 of 1,420 people in the labour force); (b) public administration (90 people); and (c) accommodation and food service (85 people; Statistics Canada, 2011d). Many people in these occupational categories are shift workers.

\section{Methods}

\section{Information Sessions and Survey Distribution}

Prior to the survey, community information sessions were conducted to gather information regarding child care in the Elk Valley, as well as to brief interested community members regarding the intent of the survey and time frames for participation. Newspaper articles, social media, posters, and word of mouth were used to announce the first round of information sessions. Fortyseven people attended the sessions and provided their perspectives on child care in the Elk Valley. Parents, child care providers, employers, and other interested community members were represented. Additionally, separate interviews were conducted with key stakeholders, including parents, child care providers, employers, staff members of the East Kootenay Child Care Resource and Referral Program (EKCCRR), and those involved in the East Kootenay Child Care Needs Assessment Project (a similar project in Cranbrook, a nearby town). Input from these sources enriched the survey consultant's understanding of current child care issues in the Elk Valley, and contributed to the development of a priori hypotheses to be assessed following data collection.

Approximately 1 month following the conclusion of the first round of community information sessions, the Elk Valley Child Care Barriers and Opportunities Survey was available for respondents to complete. The survey was open for participation for 1 month, in June and July of 2015. Participation was solicited through newspaper articles and advertisements, radio advertisements, flier distribution through area schools, advertisement on the Elk Valley/Crowsnest Pass Communities of Interest Advisory Initiative website, social media, community posters, community partners (such as a public health office, local businesses, the Chamber of Commerce, and parenthood groups), distribution with Teck Coal Limited pay stubs and staff email distribution lists, and word of mouth. Participation was voluntary and met criteria outlined by the Declaration of Helsinki. Respondents were informed that it was not necessary to be a parent in order to complete the survey, and there were separate sections of the survey for parents/guardians/primary caregivers, child care providers, employers, and other interested community members. A second round of community information sessions occurred during the time that the survey was available for participation.

\section{Data Collection and Analyses}

Data were primarily collected online, using SurveyGizmo online survey software (SurveyGizmo, Boulder, CO) with display logic to ensure that participants were only asked 
questions relevant to their circumstances. Diagnostics provided by SurveyGizmo indicated that the survey had low fatigue and high accessibility scores, and estimated that it would take an average of 22 minutes for respondents to complete. Paper copies, which included all questions in the survey, were also available for pick-up and drop-off at two locations in each community (libraries, community centres, recreation centres). Respondents were anonymous if they chose to be, but had the option to provide contact information in order to receive the results of the survey. Only the survey consultant had access to participant identities, if provided.

Raw data were compiled into a report generated by SurveyGizmo, and were also exported for further analyses. Analyses were performed using IBM SPSS 23 software (IBM, Armonk, NY) and QuickCalcs online software (GraphPad Software, San Diego, CA). Open field data were categorized as described, or were quoted verbatim where indicated. Data from the three communities were combined for overall analyses when appropriate, which was the case for most questions. Separate recommendations were presented to each community, but the present report discusses findings for the three communities combined.

\section{Participants}

Of 411 surveys started, 302 were completed, for a completion rate of 73.5\%. However, IP address data were not analyzed, so it is possible that some of the incomplete surveys represent respondents who later returned to complete the survey. Of the 302 completed surveys, 296 were completed online and 6 were completed using the paper forms. There were 209 women (69.2\%), 50 men (16.6\%), and 43 people (14.2\%) who either indicated that they preferred not to give their gender, or who skipped this question.

The survey was open to people who live or work in the Elk Valley. The three main communities of interest were each represented, with 134 (44.4\%) participants from Fernie, 79 (26.2\%) from Sparwood, 71 (23.5\%) from Elkford, and 18 (5.9\%) from other communities including Hosmer, Crowsnest Pass, Cranbrook, Jaffray, and Elko. The participation rates for each community are approximately representative of the Elk Valley, when compared with data from the 2011 Census of Population (Statistics Canada, 2011; $\chi^{2}=5.813, p=.0557$ ), and also achieved sample sizes that enabled separate analyses of responses from each community where appropriate.

Respondents indicated the community in which they work, study, or operate a business. Of the 278 respondents to this question, 77 (27.7\%) indicated Fernie, 100 (36.0\%) indicated Sparwood, 68 (24.5\%) indicated Elkford, and 33 (11.8\%) indicated other communities.

The majority of survey respondents (243 of 302, 80.5\%) were parents, guardians, or other primary caregivers to children. It should be noted that findings indicating numbers of children to whom particular situations apply should be interpreted with caution because multiple parents, guardians, or primary caregivers of some children may have completed the survey. Respondents were asked whether another parent to their children planned to complete the survey, and 36 of 240 respondents (15.0\%) indicated that they did. An additional 89 respondents (37.1\%) were unsure as 
to whether their children's other parent(s) planned to complete the survey. Therefore, although it is reasonable to draw conclusions regarding trends observed, the data should not be used to represent exact child care needs within the communities of the Elk Valley.

Respondents were permitted to identify multiple categories of interest in the survey. There were 31 participants who indicated that they are child care providers (10.3\%); 23 employers, recruiters, or human resources staff (7.6\%); 17 other family members to children who require care (5.6\%); 30 future parents (9.9\%); and 10 people who had other interests in completing the survey (3.3\%).

The majority of survey respondents were married, in a common-law relationship, or cohabiting with a relationship partner (78.5\%). The remaining respondents were divorced or separated (4.3\%), single never married (4.0\%), or did not answer the question (13.2\%).

Of respondents giving annual household income information, 44.0\% reported household incomes greater than $\$ 120,000$ per year (see Figure 1). For comparison, the median family income of couple-with-children families reported for the 2010 tax year was \$116,110 in Fernie (Statistics Canada, 2011e), \$115,022 in Sparwood (Statistics Canada, 2011f), and \$126,459 in Elkford (Statistics Canada, 2011d). The present sample is therefore approximately representative regarding household income. The majority (90.8\%) of survey respondents were not recipients of child care subsidies.

Respondents were employed in a variety of fields, with high representation (42\%) from the mining industry compared to the general population of the Elk Valley communities $\left(\chi^{2}=107.419\right.$, $p<.001$; Statistics Canada, 2011d, 2011e, 2011f). This high representation was anticipated given that mining is a major local industry, and because some survey recruitment strategies focussed on employees of Teck Coal Ltd.

Data from the NHS show that respondents were relatively well-educated compared to the general population of the Elk Valley (Statistics Canada, 2011d, 2011e, 2011f), with 85.5\% of the 264 respondents to this question having completed a post-secondary credential, compared to only $58.2 \%$ of the local general population $\left(\chi^{2}=175.169, p<.001\right)$. This difference from the general population of the Elk Valley is likely due to generational shifts in levels of education. The NHS data include all adults over 15 years of age, including those who are not currently in the workforce or of typical child-rearing ages.

\section{Results}

\section{Current Child Care}

Of the 243 parents, guardians, and other primary caregivers who completed the survey, 127 (52.2\%) indicated that they currently access child care for their children. Of those respondents who currently access child care, 71 (55.5\%) access it in Fernie, compared to 44 (34.6\%) in Sparwood, 
33 (26.0\%) in Elkford, and 9 (7.1\%) in other communities. Some respondents indicated that they access child care in multiple communities.

Of the 219 responses regarding frequency of child care access, respondents indicated that 73 of 219 children (33.3\%) attend full-time care (35 hours or more per week), 43 children (19.6\%) attend half-time care (20-35 hours per week), and 103 children (47.0\%) attend part-time care (less than 20 hours per week). Of the 144 respondents to this question, 59 (41.0\%) indicated that they pay for more child care than they actually require, in order to keep a space available when they need it.

Data were also collected regarding current child care schedules and types of care. Results are presented below in Figures 1, 2, and 3. Respondents had the option to select multiple schedules and types of care for each child, which was necessary in order to capture complete data on child care use and needs. Respondents currently accessing child care were asked whether any of their children access multiple care options in a single day (e.g., having a babysitter take the child to their licensed group daycare), and 35 of 138 (25.4\%) respondents indicated that this type of multiple provider child care arrangement occurs for at least one of their children.

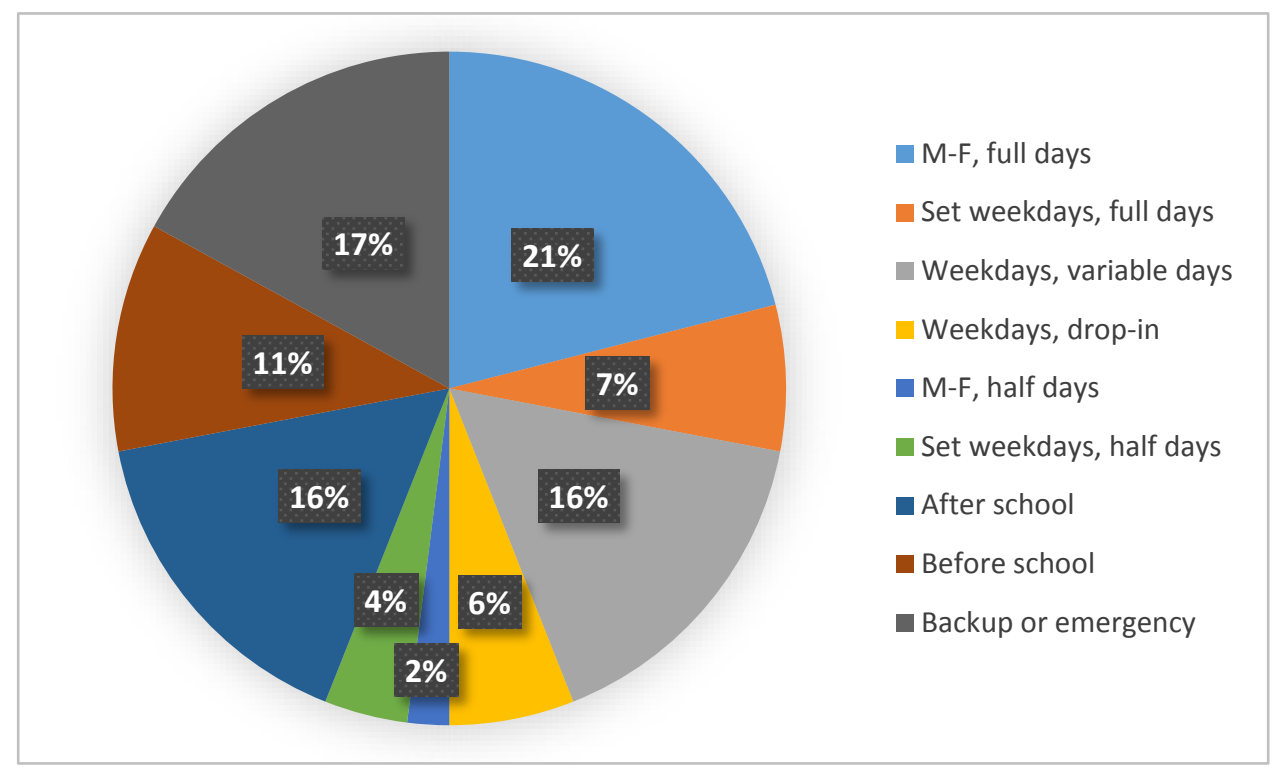

Figure 1 Current weekly child care schedules 


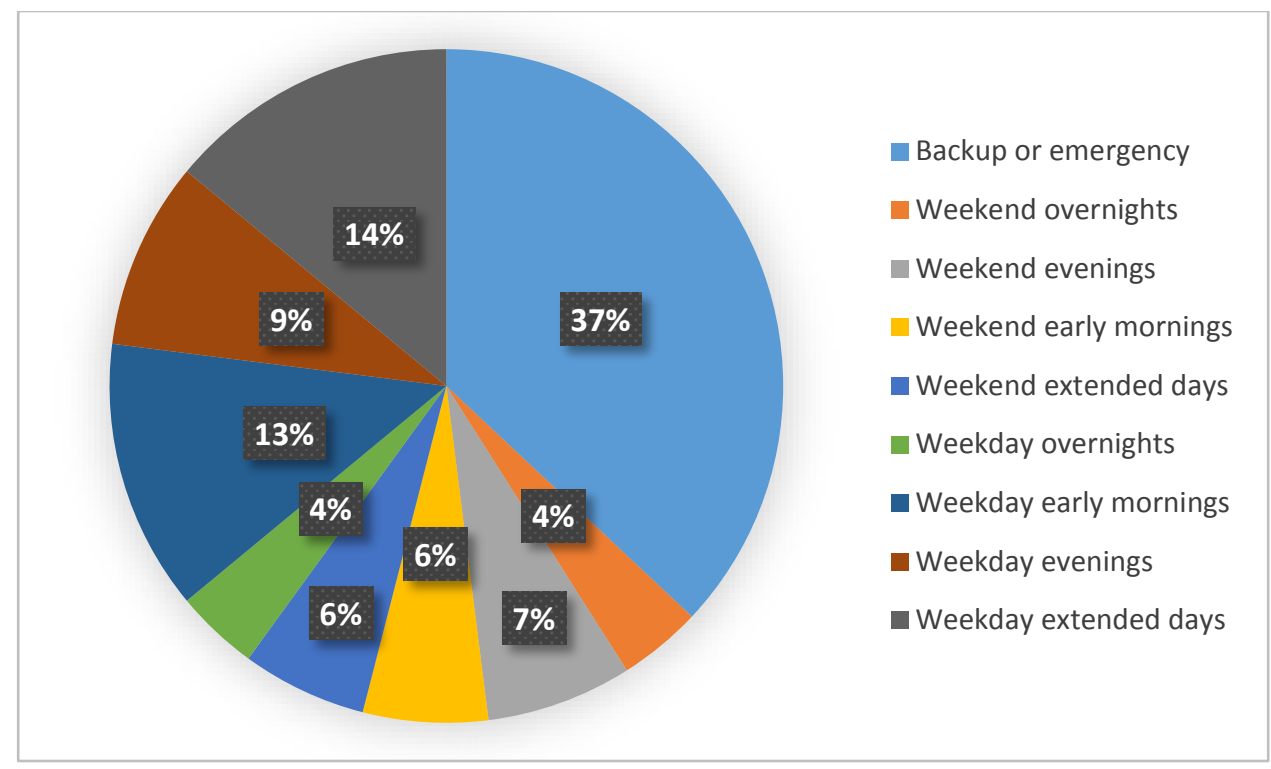

Figure 2 Current early, late, and weekend care

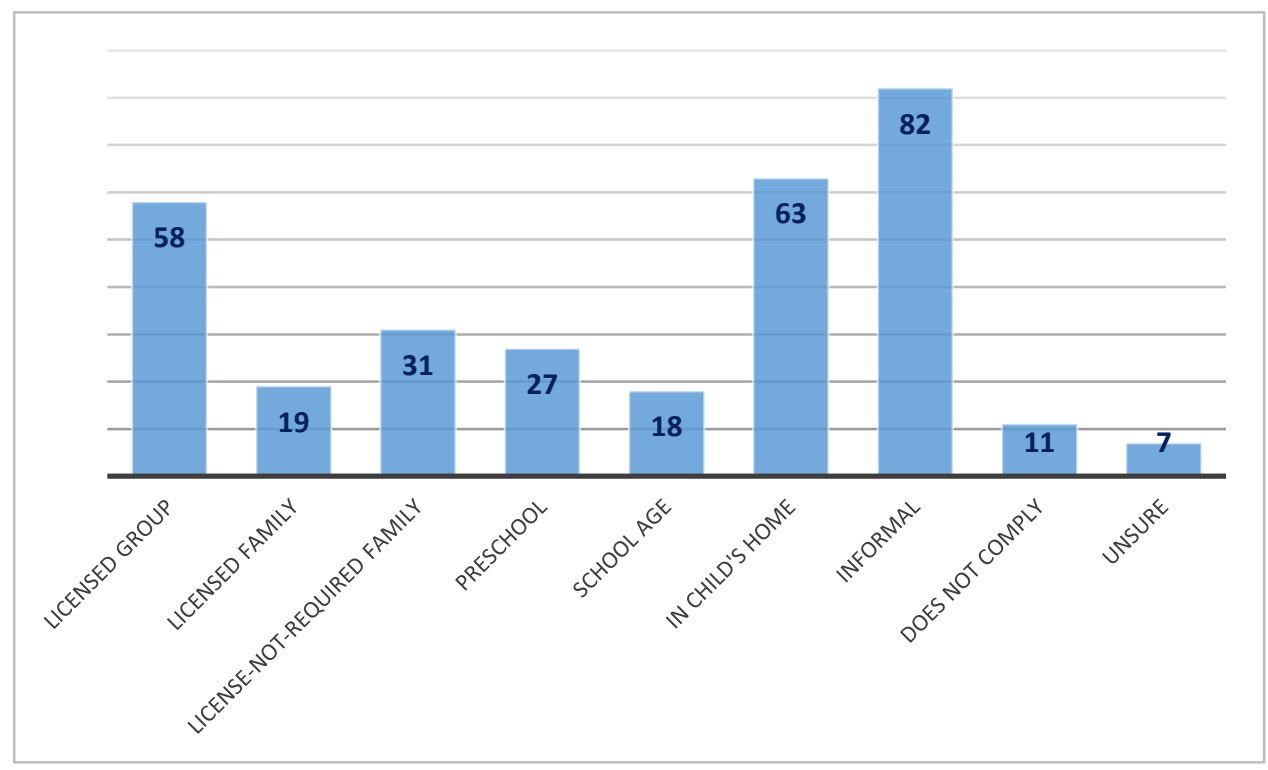

Figure 3 Current types of care accessed (number of children)

Summer care was specifically queried, as child care availability and needs often change in the summer months when children are not attending school. Of 241 respondents, 44 (18.3\%) indicated that their children require full-time summer care, and 50 of 235 (21.3\%) indicated that their children require part-time summer care. 


\section{Preferred Child Care}

When asked which communities they would access child care in if it were available, respondents indicated that they would access child care for their children in Fernie (135, 42.1\%), Sparwood (99, 31.0\%), Elkford (77, 24.0\%), and other communities (10, 3.1\%). Respondents had the option to indicate multiple communities in which they would access child care. Table 2 compares communities where respondents are currently accessing child care, with the preferred usage indicated in the survey. Given that few respondents indicated multiple communities, there appears to have been a strong preference for care in a particular community. Strategies that rely on travelling between communities are thus unlikely to meet child care needs, even in these communities that are relatively nearby to each other.

Table 2 Current Versus Preferred Child Care by Community

\begin{tabular}{lcccc}
\hline Community & $\begin{array}{c}\text { Current } \\
\text { Frequency }\end{array}$ & Current \% & $\begin{array}{c}\text { Indicated } \\
\text { Frequency }\end{array}$ & Indicated \% \\
\hline Fernie & 71 & 55.5 & 135 & 42.1 \\
Sparwood & 44 & 34.6 & 99 & 31.0 \\
Elkford & 33 & 26.0 & 77 & 24.0 \\
Other & 9 & 7.1 & 10 & 3.1 \\
\hline
\end{tabular}

Parents, guardians, and other primary caregivers were asked the frequency of child care required for children who are not currently accessing child care. They indicated a total current need for 153 full-time spaces (35 hours or more per week), 117 half-time spaces (20-35 hours per week), and 78 part-time spaces (less than 20 hours per week). Parents, guardians, other caregivers, and future parents were also asked to indicate the child care schedules and types of care that they anticipated needing in the future. Data are presented below in Figures 4, 5, and 6, with findings demonstrating a clear preference for licensed group child care. 
International Journal of Child, Youth and Family Studies (2017) 8(1): 42-73

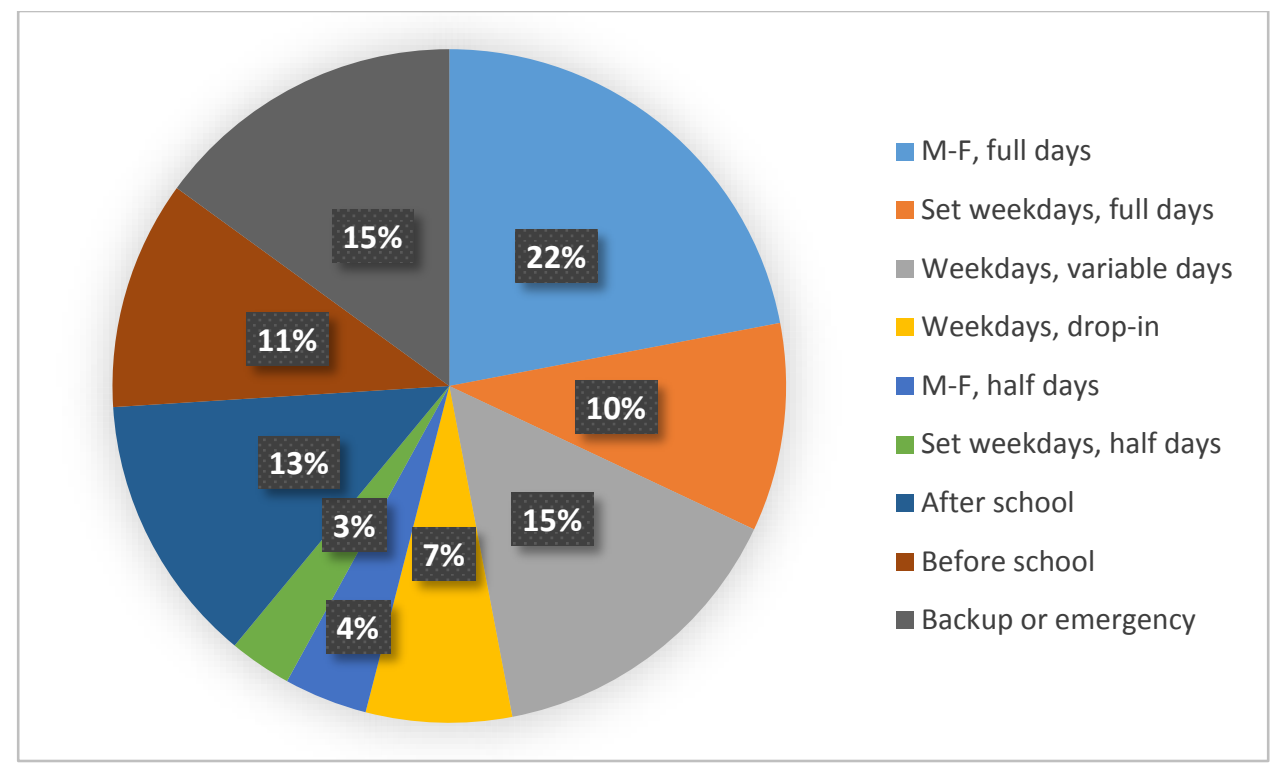

Figure 4 Anticipated child care schedules required

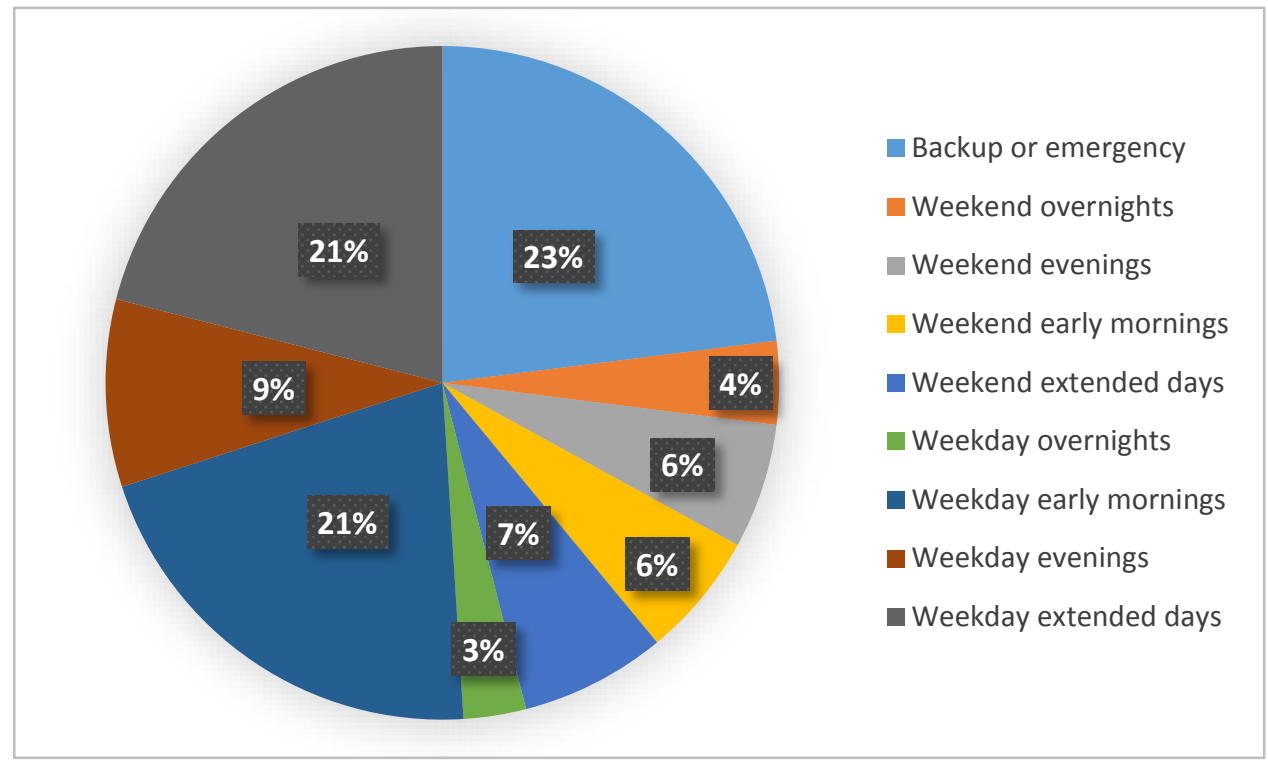

Figure 5 Anticipated early, late, and weekend care required 


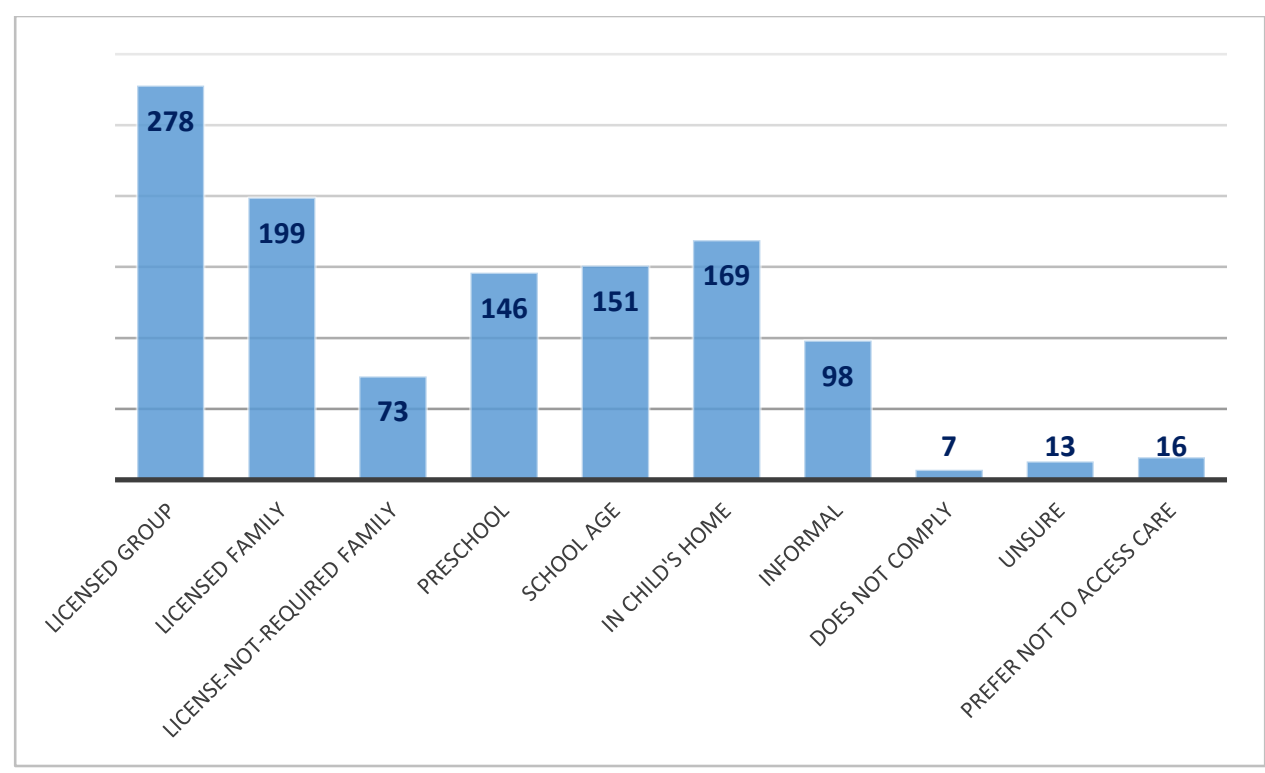

Figure 6 Preferred access to future child care (number of children)

\section{Special Needs}

Respondents were asked whether any of their children have special requirements that impact child care. Of the 240 people who answered this question, 18 (7.5\%) indicated that at least 1 child has special child care requirements, and 21 (8.8\%) of respondents were unsure. Future parents and those who plan to have more children would not be able to accurately predict whether their children will have special care requirements; therefore, the estimates are likely minimized. Those who indicated special child care requirements were asked to provide details of need, and gave answers including allergies and food intolerances (8), developmental disabilities including autism (3), needs related to speech disabilities (2), behavioural concerns (1), and being a nonnative English speaker (1). Special needs related to developmental delays and behavioural issues are maximally addressed in licensed group child care settings, as this is the only type of care setting in which supported child development programs can occur.

\section{Child Care Affordability}

Given that affordability was a specific area of interest in the current survey, respondents were asked the maximum amount per month that they would be willing to pay for child care, per child, based on an average of 40 hours per week of high-quality care that meets their family's needs. Only 104 of 234 respondents (44.4\%) indicated that they would be willing to pay rates comparable to current child care fees (over $\$ 700$ per child for full-time care) in the Elk Valley (Figure 7). Therefore, costs of care must be considered in strategies aiming to increase accessibility to child care. 


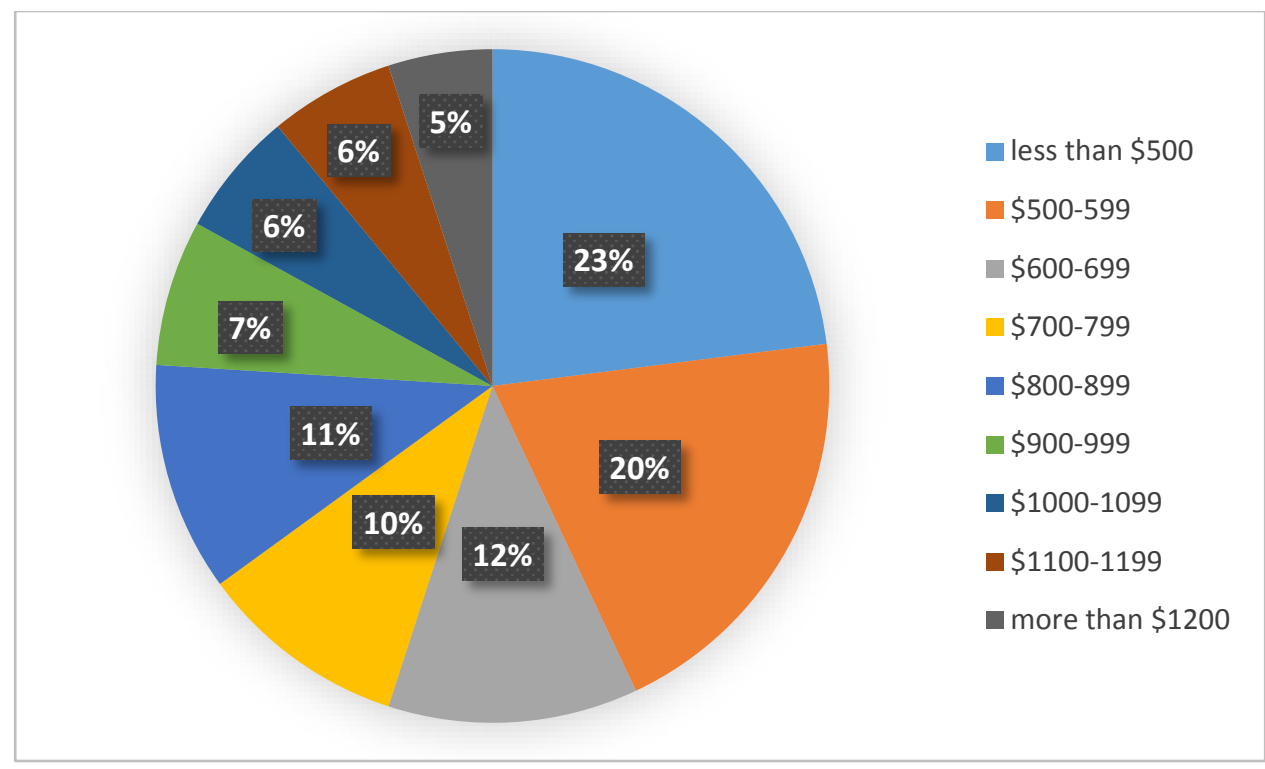

Figure 7 Fee levels that parents, guardians, and primary caregivers are willing to pay

\section{Barriers to Child Care}

All survey respondents were asked whether they feel that there are currently barriers to accessing child care in the Elk Valley. Only 3 of 278 respondents (1.1\%) indicated that they do not feel that there are barriers. The vast majority of participants $(255,91.7 \%)$ indicated that they feel that there are barriers, and 20 (7.2\%) of participants were unsure.

Respondents who indicated that there are barriers, or who were unsure, were first asked to complete an open-field question regarding the current barriers. Common responses were related to the limited number of spaces available, the length of time on waiting lists, scheduling issues (particularly regarding early mornings and extended days related to shift work schedules), lack of qualified child care providers, cost of care, lack of available infant and toddler care, staff turnover, and lack of part-time or variable-schedule care. Examples of open-field responses are presented in the Anecdotal Findings section of this report. Following the open-field question, respondents were asked to rate their level of concern regarding predefined child care issues, using a slider bar to indicate responses between 0 (no concern) and 10 (maximum concern). Means, standard deviations, and number of responses are indicated below in Table 3 . The findings demonstrate that respondents had the greatest concern (8.41/10) regarding the number of spaces available, but moderate to high levels of concern were indicated for all child care issues that were queried. Quantitative data obtained from ratings of concern with the predefined categories demonstrated similar concerns to those in the qualitative open-field format question. 
Table 3 Participant Levels of Concern Regarding Child Care Issues

\begin{tabular}{lccc}
\hline \multicolumn{1}{c}{ Child care issue } & Average (mean) & $\begin{array}{c}\text { Standard } \\
\text { deviation }\end{array}$ & $\begin{array}{c}\text { Number of } \\
\text { responses }\end{array}$ \\
\hline Number of spaces available & 8.41 & 2.34 & 260 \\
Hours available & 7.74 & 2.62 & 248 \\
Days of the week available & 5.86 & 3.26 & 230 \\
Availability of part-time care & 6.85 & 3.04 & 187 \\
Availability of care on variable days & 7.03 & 3.32 & 245 \\
Cost & & & 239 \\
Quality of care & 7.93 & 2.49 & 224 \\
$\begin{array}{l}\text { Safety and monitoring of care } \\
\text { providers }\end{array}$ & 7.58 & 2.80 & 227 \\
Staff training and qualifications & 7.10 & 3.02 & 217 \\
Communication or access to & & 2.83 & 234 \\
information & 7.25 & 2.85 & \\
Stability or longevity of care & 6.46 & & \\
\hline
\end{tabular}

Respondents were also asked a series of questions to assess the impact of child care unavailability on their choices to live or work in the Elk Valley, as well as decisions related to their employment status. Data are summarized below in Table 4. The data demonstrate that many respondents have experienced adverse impacts on their employment due to child care issues; in several cases, these issues have resulted in unemployment, despite the respondent's desire to participate in the workforce.

Anecdotal reports and the survey findings revealed strategies that parents use to compensate for child care unavailability. For example, many parents, guardians, or other primary caregivers rely on family or friends to supplement formal child care. Others share child care with another family (either sharing a child care space or caring for each other's children at different times), while some couples work opposite shifts to ensure child care coverage. The survey data revealed that 69 of 221 (31.2\%) respondents work opposite shifts from their spouse or their children's other parent in order to ensure child care coverage. While this strategy ensures that child care needs are met, anecdotal findings indicate that working opposite shifts places significant stress on families. 
Table 4 Child Care as it Relates to Community Choice and Employment Status

\begin{tabular}{lcc}
\hline \multicolumn{1}{c}{ Decision (self or spouse) } & $\begin{array}{c}\text { Number of respondents } \\
\text { impacted }\end{array}$ & \% of total respondents \\
\hline $\begin{array}{l}\text { Choice of community to live in, within } \\
\text { Elk Valley }\end{array}$ & 53 & 19.3 \\
$\begin{array}{l}\text { Considered moving from Elk Valley } \\
\text { Not seeking employment }\end{array}$ & 101 & 37.1 \\
$\begin{array}{l}\text { Quit job or retired early } \\
\text { Declined job offer }\end{array}$ & 74 & 60.2 \\
$\begin{array}{l}\text { Limited career opportunities or } \\
\text { promotion }\end{array}$ & 95 & 31.5 \\
$\begin{array}{l}\text { Not returning to work following parental } \\
\text { leave }\end{array}$ & 132 & 41.9 \\
$\begin{array}{l}\text { Unemployed to care for children, but } \\
\text { would prefer to be employed }\end{array}$ & 63 & 56.2 \\
\hline
\end{tabular}

Additionally, 8 of 221 (3.6\%) of respondents indicated that they have school-age children at home unsupervised due to the lack of available child care options, despite feeling that the children should have adult supervision. An additional 4 of 221 (1.8\%) of respondents indicated that they would prefer not to say whether this scenario occurs in their family. This issue was raised as a topic of concern during the first round of community information sessions, and although it does not apply to a large number of respondents, it is nonetheless concerning.

Many survey respondents rely on informal child care when it is available, such as that provided by extended family, trusted neighbours, and friends. Of the respondents to this question, 116 of 239 (48.5\%) had informal care available, primarily for infrequent or back-up care. However, they did also express hesitation over using these child care options, and examples of these hesitations are given in the Anecdotal Findings section of this report. The responses to this question also indicate that $50.5 \%$ of respondents have no informal care options available.

The perceived negative effects of child care on various aspects of work, family, and community life were assessed by asking respondents to use a slider bar to indicate negative effects from 0 (no negative effect) to 10 (maximum negative effect). Participant responses are given in Table 5, and indicate that the most negative impact of child care is on household budgets (6.92/10). Respondents indicated moderately negative effects of their child care situation on other aspects of life, including mental health (5.66/10) and time together as a family (5.58). 
Table 5 Perceived Negative Effects of Child Care

\begin{tabular}{lccc}
\hline \multicolumn{1}{c}{ Aspect of life } & Average (mean) & $\begin{array}{c}\text { Standard } \\
\text { deviation }\end{array}$ & $\begin{array}{c}\text { Number of } \\
\text { responses }\end{array}$ \\
\hline Productivity at work & 5.28 & 3.20 & 158 \\
Work-life balance & 5.33 & 3.24 & 177 \\
$\begin{array}{l}\text { Mental health (e.g. stress, anxiety, } \\
\text { depression) }\end{array}$ & 5.66 & 3.21 & 182 \\
$\begin{array}{l}\text { Sense of belonging in the community } \\
\text { Attachment to the community }\end{array}$ & 4.18 & 3.20 & 145 \\
& 4.25 & 3.20 & 142 \\
Household budget & & & 131 \\
Safety and security & 6.92 & 2.95 & 151 \\
Overall quality of life & 5.04 & 3.13 & 148 \\
Time together as a family & 5.10 & 3.11 & 3.30 \\
\hline
\end{tabular}

\section{Child Care Opportunities}

The majority of respondents indicated that they feel there are barriers to accessing child care in the Elk Valley; however, they did give approximately neutral responses when asked to use a slider bar from 0 (no positive impact) to 10 (most positive impact) to indicate perceived positive impacts of child care on aspects of their work, family, and community lives. The response data are presented in Table 6. Respondents indicated feeling most positively regarding the effects of child care on overall quality of life.

Survey respondents were asked questions to assess potential solutions to child care issues. When asked whether they would be interested in job sharing, 124 of 237 respondents (52.3\%) indicated that they would be interested in this possibility, and an additional 40 people (16.9\%) indicated that they were unsure. Job sharing was described in the survey question as a situation where two employees share the same position and responsibilities, each working a portion of the position hours. 
Table 6 Perceived Positive Effects of Child Care

\begin{tabular}{lccc}
\hline \multicolumn{1}{c}{ Aspect of life } & Average (mean) & $\begin{array}{c}\text { Standard } \\
\text { deviation }\end{array}$ & $\begin{array}{c}\text { Number of } \\
\text { responses }\end{array}$ \\
\hline Productivity at work & 4.72 & 3.19 & 102 \\
Work-life balance & 5.00 & 3.21 & 117 \\
$\begin{array}{l}\text { Mental health (e.g. stress, anxiety, } \\
\text { depression) }\end{array}$ & 4.50 & 3.31 & 107 \\
Sense of belonging in the community & 3.98 & 3.06 & 112 \\
& & 3.11 & 108 \\
Attachment to the community & 4.11 & 3.51 & 94 \\
Household budget & 3.72 & 3.28 & 97 \\
Safety and security & 4.75 & 3.24 & 104 \\
Overall quality of life & 5.12 & 3.32 & 98 \\
Time together as a family & 5.02 & & \\
\hline
\end{tabular}

Anecdotal reports from the initial community information sessions indicated that there may be people living in the communities who are trained in early childhood education but who do not work as child care providers. Survey results found that there are at least 10 ECEs in the Elk Valley who are not currently working in child care, and 12 people who have qualifications to work as ECEs with infants/toddlers or children with special needs, but who are not currently doing so. When asked the reasons for not working in child care or for not using their infant/toddler or special needs training, respondents indicated that they do not have child care for their own children, that they would not make enough to pay for child care for their own children, or that they have had challenges with licensing regulations. As discussed in the introduction, the regulations for ECE qualification differ between provinces. Some of these trained ECEs did not receive their education in $\mathrm{BC}$, and therefore may be required to take additional courses in order to demonstrate credentials accepted by the Early Childhood Educator Registry of BC.

An additional 27 people indicated that they currently do not have qualifications to work as an ECE, but that they would be interested in working in the child care field. Furthermore, 77 of 239 respondents (32.2\%) indicated that they would be interested in caring for another person's children in their home on some days, if that person cared for their children on other days. An additional 40 people (16.7\%) indicated that they were unsure whether they might be interested in a child care trading arrangement. If support was available to navigate regulations for becoming a licensed family daycare or to comply with LNR family care, 40 people indicated that they might be interested in providing this type of care, and an additional 40 people were unsure. Respondents were asked whether they would be interested in hiring a live-in nanny to care for children in their 
own home, provided that it was cost effective and that they had support with finding the right person, and 110 of 238 respondents (46.2\%) indicated that they are interested in this option. An additional 35 respondents (14.7\%) were unsure. Overall, these data indicate that the respondents were quite open to exploring a variety of child care arrangements that could meet their needs.

Respondents expressed a high level of interest in employers offering child care on-site or near to work sites, if such care were comparable in price to other available options. A total of 193 of 238 respondents (81.1\%) indicated that they would be very likely or somewhat likely to have interest in using child care offered by their employer.

\section{Responses of Child Care Providers}

The survey included questions designed to assess perspectives of child care providers. Thirty-one respondents categorized themselves as child care providers; this number included some not currently employed as child care providers. The ones who were employed worked in a variety of care models, the majority at licensed group child care facilities. Data on types of child care provided by survey participants are presented in Figure 8.

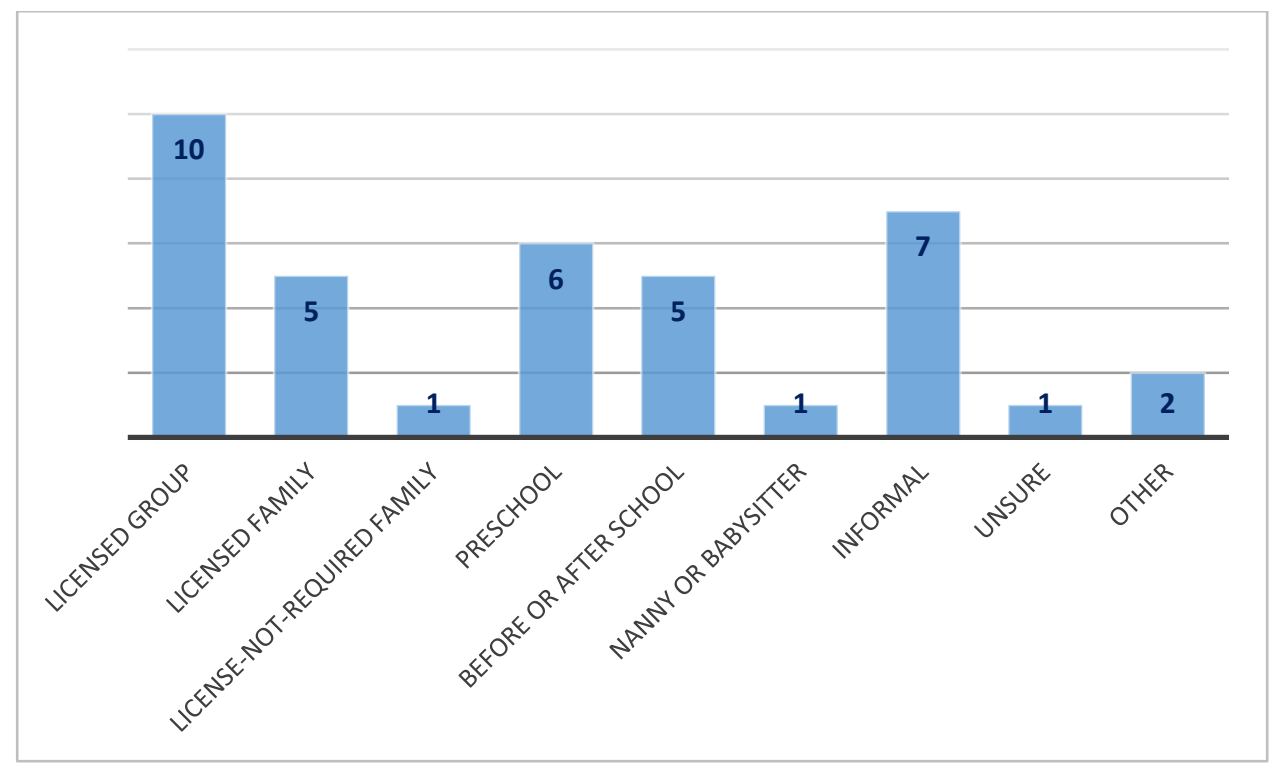

Figure 8 Types of child care provided (number of providers)

Child care providers were asked to indicate their highest level of education in child care. Of 25 respondents, 20\% were ECE certified with infant/toddler or special needs certification, 36\% had ECE certification, 12\% were ECE Assistants, 4.0\% had the "responsible adult" designation, and $28.0 \%$ had no ECE education.

Child care providers were asked whether they plan to be working in child care 5 years from now, with 13 of 26 respondents (50.0\%) responding “yes,” 5 of 26 (19.2\%) responding “no,” and 8 of 26 (30.8\%) being unsure. Reasons for not working in child care in the future are summarized in Figure 9. 


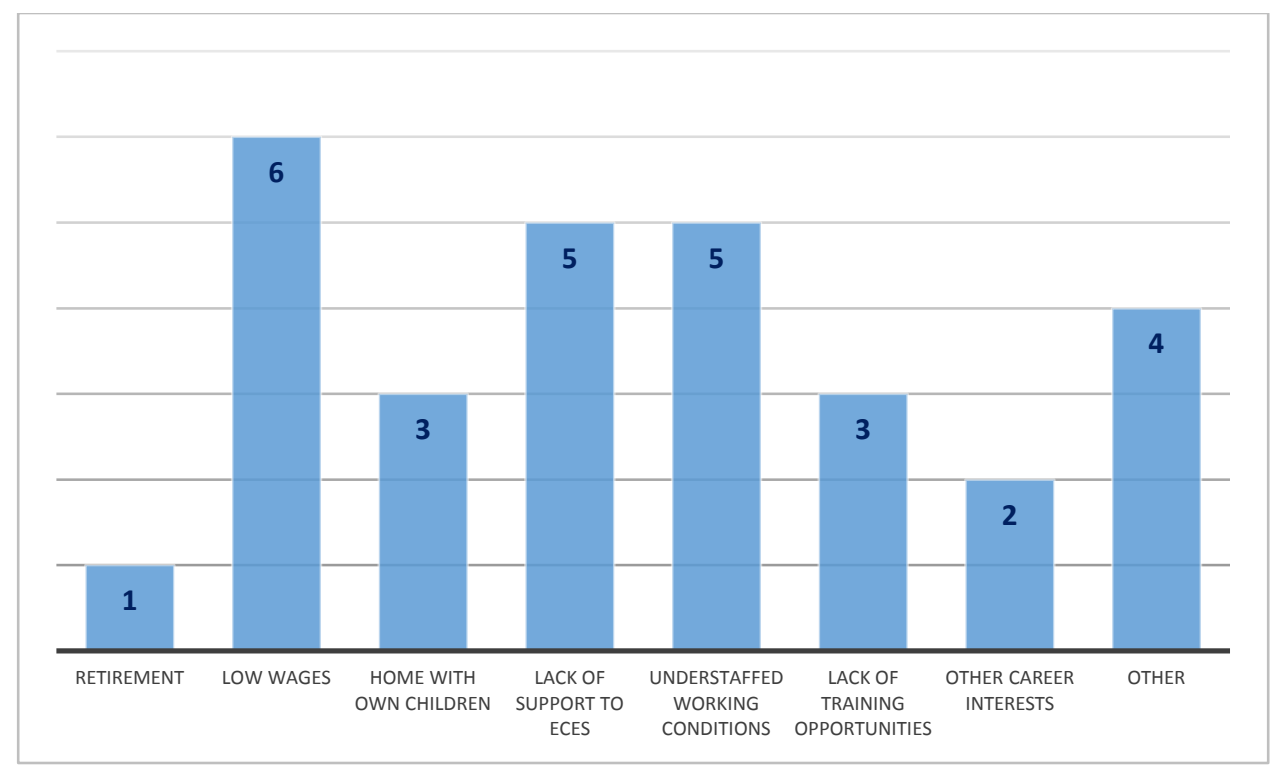

Figure 9 Reasons for leaving child care field (number of respondents)

Child care providers were asked to indicate their level of concern regarding issues related to their profession, using a slider bar from 0 (no concern) to 10 (maximum concern). This data is summarized below in Table 7. Findings indicate that low wages are the most concerning issue for child care providers (9.32/10), which was supported by the open-field responses.

Table 7 Concerns of Child Care Providers

\begin{tabular}{lccc}
\hline \multicolumn{1}{c}{ Provider issue } & $\begin{array}{c}\text { Average } \\
\text { (mean) }\end{array}$ & $\begin{array}{c}\text { Standard } \\
\text { deviation }\end{array}$ & $\begin{array}{c}\text { Number of } \\
\text { responses }\end{array}$ \\
\hline Low wages & 9.32 & 1.25 & 20 \\
Lack of training opportunities & 5.97 & 2.48 & 18 \\
Lack of support to ECEs as professionals & 7.47 & 2.16 & 17 \\
Understaffed working conditions & 8.08 & 2.15 & 16 \\
Job instability & 4.11 & 3.78 & 11 \\
Other & 7.28 & 2.09 & 4 \\
\hline
\end{tabular}

The challenges experienced by child care providers were further explored by investigating reasons for the scarcity of available spaces. Of 15 respondents who worked at centres with hired staff, 14 (93.3\%) indicated that their child care centre has challenges with finding qualified staff. Additionally, 6 of 16 respondents (37.5\%) indicated that finding or maintaining appropriate space is a challenge. Respondents were asked whether there is a waiting list to begin child care at their 
centre. Of the 17 respondents to whom the question applied, 15 (88.2\%) said “yes.” Furthermore, child care providers confirmed that preference is often given to families using full-time spaces rather than part-time spaces, with $76.9 \%$ of applicable providers indicating registration preference for children who attend full-time.

\section{Employer Perspectives on Child Care}

An aim of the survey was to investigate employer perspectives on child care. The survey respondents included 23 employers, recruiters, or human resources staff, and 17 of 21 of these respondents (81\%) indicated that they have employees who require care for their children. Table 8 presents survey data regarding child care issues from an employer perspective, based on reports from their employees. Employers indicated whether the listed events had occurred, specifically as a result of employees or potential employees not having child care for their children. Although this is a small sample of employers, 9 of 20 (45\%) employers, recruiters, or human resources staff reported that they had cancelled a service offered by the business, closed temporarily, or had dayto-day business operations otherwise impacted by the absence of an employee due to child care issues.

Table 8 Experiences of Employers Related to Employee Child Care

\begin{tabular}{lcc}
\hline \multicolumn{1}{c}{ Child care issue } & \% reporting issue & $\begin{array}{c}\text { Proportion of total } \\
\text { responses }\end{array}$ \\
\hline Missed work in past 1 year & 76.2 & $16 / 21$ \\
Quit job in past 3 years & 28.6 & $6 / 21$ \\
Did not return from parental leave in past 3 years & 33.3 & $7 / 21$ \\
& & $5 / 21$ \\
Declined job offer in past 3 years & 23.8 & \\
\hline
\end{tabular}

Employer respondents were asked whether they offer any assistance to their employees regarding child care, and 3 of 21 (14.3\%) indicated that they do. Specific assistance offered included special leave for caring for ill children (2) and discounted child care rates for employees at a child care centre (1).

\section{Responsibility for Child Care Issues}

Survey respondents were asked who they feel should be responsible for ensuring that child care needs are met in the Elk Valley. The findings summarized in Table 9 indicate that the majority of respondents feel that addressing child care solutions should be a partnership with several contributors, including community organizations, parents, guardians, and primary caregivers, employers, child care providers, and all levels of government. Of those respondents who indicated 
that a specific contributor should be taking on a leadership role, municipal and provincial government were most commonly identified as preferred leaders.

Table 9 Perceived Responsibility for Finding Solutions to Child Care Issues

\begin{tabular}{|c|c|c|c|c|c|c|}
\hline Contributor & $\begin{array}{l}\text { Not at all } \\
\text { responsible }\end{array}$ & $\begin{array}{c}\text { Minor } \\
\text { contributor }\end{array}$ & $\begin{array}{c}\text { One of } \\
\text { several } \\
\text { contributors }\end{array}$ & $\begin{array}{l}\text { A leader in } \\
\text { finding } \\
\text { solutions }\end{array}$ & $\begin{array}{l}\text { Solely } \\
\text { responsible }\end{array}$ & $\begin{array}{l}\text { Number of } \\
\text { respondents }\end{array}$ \\
\hline $\begin{array}{l}\text { Parents and other } \\
\text { family members }\end{array}$ & $4.2 \%$ & $12.7 \%$ & $48.5 \%$ & $28.5 \%$ & $6.2 \%$ & 260 \\
\hline $\begin{array}{l}\text { Organizations that } \\
\text { provide child care }\end{array}$ & $1.6 \%$ & $3.9 \%$ & $45.1 \%$ & $46.7 \%$ & $2.7 \%$ & 255 \\
\hline Employers & $5.0 \%$ & $12.4 \%$ & $45.7 \%$ & $34.9 \%$ & $1.9 \%$ & 258 \\
\hline $\begin{array}{l}\text { Community } \\
\text { organizations }\end{array}$ & $6.0 \%$ & $11.1 \%$ & $56.3 \%$ & $26.2 \%$ & $0.4 \%$ & 252 \\
\hline $\begin{array}{l}\text { Municipal } \\
\text { government }\end{array}$ & $1.9 \%$ & $5.8 \%$ & $34.2 \%$ & $50.6 \%$ & $7.4 \%$ & 257 \\
\hline $\begin{array}{l}\text { Provincial } \\
\text { government }\end{array}$ & $3.5 \%$ & $5.4 \%$ & $31.4 \%$ & $50.8 \%$ & $8.9 \%$ & 258 \\
\hline $\begin{array}{l}\text { Federal } \\
\text { government }\end{array}$ & $7.0 \%$ & $10.2 \%$ & $31.3 \%$ & $43.4 \%$ & $8.2 \%$ & 256 \\
\hline
\end{tabular}

\section{Anecdotal Findings}

In the process of gathering background information for the survey design, during interviews with key stakeholders, and through open-field responses to the survey, it became clear that the full scope of the issues regarding child care cannot be fully elucidated without considering the personal experiences of individuals in the context of the group data. In many cases, the impact on families and care providers could be observed in the emotional recounting of events related to child care. Participants in these discussions felt that ensuring access to high-quality child care is a critical aspect of community sustainability, and often made comments about the impacts of child care issues on their mental health, their children's development, and gender equity in the workplace and in society. The majority of survey respondents gave anecdotal or open-field responses. The selected comments below are representative of the open-field responses to the survey.

I believe the responsibility for the education of all children begins when they are born, not when they turn 5, therefore I believe we need universal child care in Canada. We do the best we can with wages and funding, but unless we have more we will never achieve the quality of care our children deserve. 
It's hard to keep child care providers in an area where they can make more driving truck.

Lack of child care is why I am unemployed. I don't have a choice. I have also done child care for others as they don't have options for child care. It is a terrible situation for a lot of women, who can feel quite trapped or stuck.

I didn't know before I had kids that the hardest thing about being a parent would be not being able to work. I believed that I could have both.

I'd love to stay working as an ECE, but I wouldn't make enough to pay for child care for my own kids. Besides, there probably wouldn't be a space available for them anyway.

There is no child care that coordinates with [employer] schedules.

We have had luck finding local nannies who we trust, but have had five in 18 months, all who have moved on for reasons unrelated to the job. This creates a lot of stress and change for our family, and makes it challenging to provide extra commitment or flexibility to our employer.

I have a master's degree in educational studies and have been a hands-on stay at home mother for 13 years. This however does not count as valid child care experience to the licensing board. This means that I am not fully qualified to work with children. If the licensing rules accepted other types of qualifications then there might be more available child care workers. The pay scale of an ECE does not make retraining an economically viable option.

There are not enough licensed [workers] at EDUCATED child care facilities. We have a lot of stay at home moms that take on children, but I personally want my children in a regulated environment with safety, learning, and schedule standards. And the ones that are here, with certified and educated staff are so expensive it's not plausible.

Not enough day care facilities have forced me to stay at home with child during the day and work evenings only. I'm unable to work full-time as my husband already works and is away during the day.

Either myself or my husband will need to quit our job if we don't find care soon. We both really like our jobs and have worked hard to get our careers established.

I feel that setting up a strong system of child care is extremely important for the next stage of achieving gender equality in the workplace. 
Our family has been seeking child care for our first born since we were 8 weeks pregnant, the search is still ongoing and our first born is 1 at the end of this month. It has made our first year of parenthood stressful and worry stricken.

We used three different day homes in Sparwood prior to 2013; in 2013 my mother moved to the Valley to act as a live-in nanny for us.

Hours of operation for commuting parents to [employer location] need to coincide with shift schedules including travel times.

Anything you can afford comes without a receipt so you can't claim it, so not really all that cost effective.

If [employer] wants to retain employees in the Valley, they need to get involved with making quality child care accessible.

There is a lack of government support on provincial and especially municipal levels ... for licenced daycare spots.

For new parents there is little information to help prepare you for child care issues ... I put my son on the waitlist when he was 2 months old and after 9 months he is still in the teens on the wait list ... I suggest having a centralized place to find out information on available private day homes, rather than it being a case of who knows who having more access to child care. To me that makes child care less accessible for it is a bit of a private club.

Why would anyone go into the child care field, they will be paying off student loans for a long duration.

My husband and I must work opposite shifts, having just 1 hour for the three of us [including child] during each day. Even our days off are not the same.

I fought with the Government of Canada over hiring a New Zealander nanny legally. In the first 6 months of work, I had 8+ sitters. I was not able to claim any of it on my taxes, because they were all on visas, or not claiming the money. I was taking home less than $\$ 200 /$ week after child care expenses.

I believe that safe, reliable, affordable child care should be mandated at the federal and provincial levels. Child care affects absolutely everyone in society - the current level of service is a barrier to productivity, family life, healthy communities, and work equality. 


\section{Discussion}

Data-based recommendations were developed, which focussed on both short- and longterm mitigation strategies. The aim of the present study was to develop strategies that can be enacted with the intent of resolving child care barriers in the Elk Valley. However, these findings are also applicable to other communities in Canada, as well as internationally.

\section{Short-term Mitigation Strategies at the Individual and Family Levels}

Short-term mitigation strategies were apparent when opportunities to organize existing resources were considered. Given the many people with identified needs for child care, it would be pertinent to develop networks of people who need child care in each community, in order to facilitate child care trading. The survey results indicate interest in this option (a total of 117 respondents indicated openness to this idea), which may help to address the needs of shift workers, and would be a low- or no-cost option for families. The disadvantages include both lack of regulation and limited capacity to organize this system. However, criteria could be developed for being part of the network, such as proof of having taken a first aid course or passing a criminal record check. Capacity may exist through existing community organizations, or a next step by the EVCCAI may be to further investigate child care co-operatives (e.g., as outlined by Babycenter, 2015) and facilitate progress in this area. Furthermore, this potential solution to some child care issues could be implemented in virtually any community, in any area or country, as a grass-roots initiative by those who need child care.

\section{Short-term Mitigation Strategies at the Community Support Level}

It may be possible to capitalize on existing community resources to create a network of trainers or support people to guide others through processes such as hiring a foreign nanny or providing LNR family care at home. The anecdotal findings of the present study indicate that there are people in the Elk Valley communities who have experience with these processes, and information sharing would likely mitigate the complications experienced by those who have not been through these processes before. This strategy likely also applies in other geographical areas, as local experts may be recruited. In the Elk Valley, the EKCCRR would be a valuable partner in this strategy, as they offer resources on these topics that would facilitate expanded information sharing (East Kootenay Child Care Resource and Referral Program, 2015). There are similar referral programs in other BC communities; places without such programs may benefit from establishing them as a first step to addressing child care issues through resource coordination.

Similarly, families would likely benefit from creation of information packages regarding cost-saving or budgeting methods as they relate to child care. It appears that some people are not aware of options such as child care subsidies or tax credits, although this may be in part due to the fact that most of the present survey respondents had income levels that make them ineligible for these programs. Nonetheless, many community members may benefit from having this information collected in a single source, and existing community organizations (such as the 
EKCCRR program in the Elk Valley) or governmental agencies have the expertise to create these information packages. Information packages should be tailored to each geographical region, whether it be a collection of municipalities or an entire country, based on pertinent child care regulations.

Both short- and long-term value would result from collaboration by local child care providers to develop a system of availability sharing, in order to reduce overpaying for unused child care and also potentially create more space to accommodate additional children. Given that some parents pay for space that they do not use in order to ensure child care when they do need it, it is likely that there are unused spaces in child care centres on a regular basis. This strategy could also reduce problems associated with preference being given to those requiring full-time care. Creating an information sharing system for child care providers may be a logical next step for the EVCCAI and similar community organizations in other provinces or countries. This option may be limited by privacy issues and regulations pertaining to information sharing, but region-specific information sharing policies could be developed to mitigate this barrier.

Given that staffing challenges were identified, a logical mitigation strategy is to promote and support the local college in offering ECE courses or programs on campus or online. This recommendation is based on the recent success of the local college (College of the Rockies, Fernie campus) in providing several people with the training requirements to provide LNR child care in their homes, or for being able to work in a licensed child care facility. Previous research across Canada has also found that supporting ECE education is a critical strategy toward resolving child care barriers (Watson, 2001). Supporting ECEs as professionals is a long-term endeavour; however, local programming could be impacted in the short term. This strategy could be applied in any community in which local colleges have the capacity to offer increased training opportunities.

Finally, short-term solutions to the child care barriers in the studied communities could be achieved by providing support to child care providers currently operating unlicensed and unregulated child care facilities, in order to promote standards for safety and confidence in the quality of care. Anecdotal reports indicate that there are several such care providers operating in the Elk Valley communities, some of whom may be eligible for registration with the EKCCRR program with little or no need for additional training or documentation. The providers who operate these child care businesses may be unaware of the standards for registration and may not be aware that they do not need to have ECE credentials or meet licensing criteria in order to be registered. Increasing the number of RLNR child care providers may make it easier for parents to find child care that they feel comfortable with, rather than relying on word of mouth. Parents would also likely be reassured by the first aid knowledge, criminal record check, and other requirements for registration. Furthermore, it is likely that unregistered care providers throughout BC could be assisted with the registration process via a provincial-level initiative, thereby increasing accessibility and parent confidence in care providers in other communities as well. 


\section{Long-term Community Development Strategies}

Residents of each of the three main communities in the Elk Valley indicated a clear preference for child care in their home community rather than the community that they work in. This finding is not surprising given the geographic distribution of the communities. Sparwood is the central community, and is $34 \mathrm{~km}$ from Elkford and $31 \mathrm{~km}$ from Fernie, for a total distance of $65 \mathrm{~km}$ between Elkford and Fernie. Additionally, employees of Teck Coal Ltd. (41\% of survey respondents) may work at mine sites that are distant from their home communities. The mine sites are up to $30 \mathrm{~km}$ away from the nearest community (Teck Coal Limited, 2015), adding to commuting time and extending the length of time that child care is required. Therefore, a strong conclusion, which impacts all recommendations based on this survey, is that it is essential for each community to have child care that fully addresses that community's needs. This finding is particularly significant because it is relevant to many communities in Canada with similar geographical distances between neighbouring communities. The implication of this finding is that relying on resources in neighbouring communities will not address child care needs.

As noted above, a lack of trained ECEs has been identified as a barrier to child care access and affordability in the Elk Valley, as well as in other communities. Therefore, in order to create sustainability, it is necessary to support the availability of trained ECEs needed to staff licensed child care facilities. Parents, guardians, and other primary caregivers of children across the Elk Valley voiced a clear preference for licensed group child care facilities. However, previous research has found that regulated child care spaces of any type are only available for $18.7 \%$ of children from birth to 12 years of age, and $22.7 \%$ of children from birth to 5 years of age in BC (Friendly et al., 2015). Across Canada, regulated child care is only available for $24.9 \%$ of birth to 12 -year-olds and $24.1 \%$ of birth to 5 -year-olds (Friendly et al., 2015). Child care providers have clearly indicated that staffing child care centres is a major challenge, as reported by $93 \%$ of child care provider respondents in the present study.

The present survey identified that there are at least 10 trained ECEs in the Elk Valley communities who are currently not working in child care; a similar situation likely exists in other communities across BC and Canada. Therefore, recruitment may focus on people who are already trained, or who require minimal upgrading to their training, in order to work in the child care field.

Recruitment strategies to train new ECEs would also be beneficial, and would be most effective if they are expanded beyond the level of individual child care centres to involve municipal government and other community partners. However, issues of recruiting new ECEs to initial training occur throughout BC, with low wages for work as an ECE and a lack of paid benefits cited as major deterrents to entering or staying in the field (Early Childhood Educators of BC, 2012). Additionally, training that occurs on a part-time basis and that accounts for the scheduling needs of those being trained would enhance the probability of new ECEs being available to work in licensed group child care facilities. Scheduling considerations should include the needs of current 
child care workers who want to upgrade their qualifications, as well as those who currently work in other fields but have an interest in working in child care.

Child care providers in the present survey indicated low wages as their primary concern within their profession, and those trained as child care providers but not currently working in the field have clearly indicated that wages are the primary reason for either not being employed or for seeking employment in other fields. Therefore, long-term strategies must support wage increases for qualified ECE staff in licensed child care facilities. There are currently well-established initiatives directed at the BC government, with aims that include wage increases for ECEs. For example, the \$10aDay Child Care Plan, by the Coalition of Child Care Advocates of BC (2015), proposes wage increases to approximately \$25 per hour plus improved benefits, as well as support to those who want to become trained ECEs. These components of the plan are based on extensive research on child care issues in BC, including surveying the membership of the Early Childhood Educators of BC. By comparison, ECEs in the Elk Valley currently earn \$14 to \$21 per hour, consistent with the median wage earned by ECEs in BC, which is within a \$16 to \$18 per hour range (Early Childhood Educators of BC, 2012). Under the \$10aDay Child Care Plan, families whose annual income is less than $\$ 40,000$ per year would not pay fees for ECE-provided child care, and the cost to families with higher incomes would be $\$ 10$ per day for full-time care or \$7 per day for part-time care. Therefore, the plan addresses concerns of both ECEs, as well as the parents and caregivers of children.

Additionally, direct strategies in specific communities, such as approaching local employers, community organizations, or funding agencies for support, may yield more rapid mitigation of the current child care barriers, yet also have considerable long-term effects. Job sharing emerged as a potential option for many families, which may reduce barriers to employment that result from limited child care options. The Elk Valley is in need of a strategy to enable women, many of whom are highly educated and skilled, to participate in the labour force; the survey data indicated that there are many women in these communities who want to work but are not able to due to child care issues. Job sharing by these women, their partners, or both, may provide opportunities for people to use their developed skills to the benefit of local employers. Additionally, the challenges facing dual-income or single-parent families working 12-hour shifts (plus commute time) must be considered in order to fully meet the child care needs of shift workers. This does not necessarily mean that children require child care for the entire duration (and licensing regulations require that this cannot occur in licensed child care settings), but hours of available care must be flexible enough to accommodate shift work schedules. Acting on this recommendation likely involves developing child care options that involve multiple care providers in a single day, whom parents feel confidence in. Other strategies to address this recommendation may include job sharing or developing a child care co-operative, as outlined above.

The specifics of labour force participation in the Elk Valley revolve around shift work schedules. Therefore, a recommendation is that major employers should be approached regarding providing opportunities for a flexible work schedule that allows parents to adjust hours around 
typical child care centre operating hours. For example, it may be possible for some employees to change their work hours from a 7 a.m. to 4 p.m. shift to an 8 a.m. to 5 p.m. shift, in order to coincide with child care hours. This recommendation is based on the fact that a single major area employer is primarily responsible for the shift work schedules that are identified as a major barrier to accessing adequate child care in the Elk Valley. Even if additional spaces were available in a licensed group child care facility with typical operating hours, these hours would not adequately address the child care needs of Elk Valley residents because they currently do not coincide with the shift schedules. This strategy may also apply to other relatively small communities with a single major employer, as the relationship between the required child care schedule and employee work hours is straightforward. Furthermore, it may be more realistic to adjust shift schedules to child care availability when possible, rather than to expand the hours of child care availability. A 2001 study reported on pilot projects by the Canadian Union of Postal Workers using a child care fund to create extended care hours (Lowe, 2001). Despite extensive funding, many parents chose not to use extended care hours because of concerns over disrupting their children's schedules with a program that may be temporary, or by using child care that would necessitate moving children during their sleep time. In Canada, the current federal Liberal government has promised to amend the Canada Labour Code to give workers the legal right to request more flexible work, including modified start and end times, as well as opportunities to work from home, without fear of reprisal (Liberal Party of Canada, 2015). Therefore, a recommendation for adjusted work schedules when possible is a realistic option for parents with young children.

In addition to the issues of creating more access to licensed group care, the present findings also emphasize the unmet need for flexibility in child care provision. Shift work and dual-income families often create the need for alternative types of care arrangements during non-standard hours, for overnight care, and for ill children. The needs for this type of care have been extensively outlined in the past (Friendly et al., 1994; Watson, 2001), but child care regulations and licensing remain prohibitive of most child care arrangements that would address these needs. Provisions for flexible child care arrangements, particularly in rural areas, have been proposed and even endorsed in most provinces across Canada (Watson, 2001). However, implementation has been only sporadically supported by various levels of government, and has yet to be fully realized. Given that the current Canadian federal Liberal government has highlighted child care issues as a component of their election platform, there may be opportunities for improved child care to be realized in Canada. In the present survey, $43.4 \%$ of respondents indicated that the federal government should be a leader in finding solutions, and $31.3 \%$ of respondents indicated that it should be one of several contributors to resolving child care barriers. Furthermore, $50.8 \%$ and $31.4 \%$ of respondents indicated that the provincial government should be a leader in finding solutions or one of several contributors, respectively. The current BC Liberal government assists families through child care subsidies, but a provincial child care strategy has not been adopted or proposed (British Columbia Liberal Party, 2013), and subsidies do not address the barriers identified in the present survey. 
Conclusions based on the present study may be limited by the fact that data were collected from three specific communities of the Elk Valley. While the obtained sample is a good size for the relevant population and has thereby provided detailed information that is highly useful in the Elk Valley communities, demographic, occupational, or geographical differences may affect the generalizability of the data to other communities in Canada and other countries. Therefore, it would be useful for future research to replicate the present survey in other communities, in order to investigate potential child care barriers and opportunities elsewhere. If similar findings occur in multiple studies, the generalizability could be extended. An additional future direction would be to more fully explore the responses of ECEs and employers to child care issues in specific communities. The conclusions of the present study are limited by sample size for these types of respondents, but obtaining more data would be useful for obtaining a more complete understanding of child care issues as they relate to employability, as well as to understanding the reasons for a lack of trained ECEs to staff child care centres. A previous study surveyed ECEs throughout BC (Early Childhood Educators of BC, 2012) and replication of that survey with community-specific data would be useful for determining local initiatives that may assist with resolving child care barriers. Finally, findings such as the preference for licensed group child care or interest in job sharing options may or may not occur in other populations, and gathering this information across a spectrum of communities would be beneficial to national or provincial child care strategies.

\section{Conclusions}

The present study described child care use, needs, barriers, and opportunities in the three communities of the Elk Valley, BC, Canada. Although the resulting data are specific to the communities studied, they are also relevant to other communities facing similar child care issues. Furthermore, the findings are consistent with issues that have been identified across Canada for several decades. The findings and resulting recommendations of this survey are practical strategies to pursue in the absence of provincial or national child care strategies. However, continued work toward large-scale solutions is necessary in order to address needs that cannot be met by community-based efforts. A combination of local initiatives and large-scale strategies would ensure that high-quality child care is accessible and affordable.

\section{Acknowledgements}

The study was fully funded by the Columbia Basin Trust. The authors also wish to thank the survey respondents, participants in the community information sessions, and key stakeholders who were interviewed during survey development. Additionally, we are grateful to our partners who provided meeting space and staff participation for the project.

\section{Disclosure}

The original study report is available online at www.ekkids.ca. 


\section{References}

Babycenter. (2015, September 6). Re: Babysitting co-ops. Retrieved from http://www.babycenter.com/0_babysitting-co-ops_51.bc

British Columbia Liberal Party. (2013). 2013 platform. Retrieved from https://www.poltext.org/sites/poltext.org/files/plateformes/bc2013lib_plt.pdf

Coalition of Child Care Advocates of BC. (2015, September 2). Re: Our plan. Retrieved from http://www.10aday.ca/our_plan

Early Childhood Educators of BC. (2012). Summary: 2012 provincial membership survey. Retrieved from http://www.ecebc.ca/membership/ProvMembSurvey_July2012.pdf

East Kootenay Child Care Resource and Referral Program. (2015, August 26). Re: Services provided. Retrieved from http://www.childcarechoices.ca/main/Interior/East+Kootenay/

Friendly, M., Cleveland, G., \& Willis, T. (1994). Flexible child care in Canada: A report on child care for evenings, overnights and weekends, emergencies and ill children, and in rural areas. Toronto, ON: Childcare Resource and Research Unit, University of Toronto.

Friendly, M., Grady, B., MacDonald, L., \& Forer, B. (2015). Early childhood education and care in Canada 2014. Toronto, ON: Childcare Resource and Research Unit. Retrieved from http://www.childcarecanada.org/publications/ecec-canada/16/03/early-childhood-educationand-care-canada-2014

Government of British Columbia. (2009). Parents' Guide to Selecting and Monitoring Child Care in BC. Victoria, BC: Ministry of Healthy Living and Sport, Ministry of Children and Family Development. Retrieved from http://www.health.gov.bc.ca/library/publications/year/2011/Parents'_guide_to_selecting_an d_monitoring_child_care_in_BC.pdf

Invanova, J. (2015). Solving BC's affordability crisis in child care: Financing the $\$ 10$ a day plan. Vancouver, BC: Canadian Centre for Policy Alternatives.

Liberal Party of Canada. (2015). Real change: Greater economic security for middle class families. Ottawa, ON. Retrieved from http://www.liberal.ca/files/2015/09/Greatereconomic-security-for-Canadian-families.pdf

Lowe, E. (2001). When shift work is the norm: An interview with Jamie Kass. Interaction: Publication of the Canadian Childcare Federation, 14(4), 30-32. Retrieved from http://www.peelearlyyears.com/pdf/Flexible\%20Child\%20Care,\%20Manual.pdf 
International Journal of Child, Youth and Family Studies (2017) 8(1): 42-73

Statistics Canada. (2011a). Census profile: Elkford. Retrieved from http://www12.statcan.gc.ca/census-recensement/2011/dp-pd/prof/details/ page.cfm?Lang=E\&Geo1=POPC\&Code1=1143\&Geo2=PR\&Code $2=59 \& D a t a=C o u n t \& S e a$ rchText=Elkford\&SearchType=Begins \&SearchPR=01\&B1=All\&Custom=\&TABID=1

Statistics Canada. (2011b). Census profile: Fernie. Retrieved from http://www12.statcan.gc.ca/census-recensement/2011/dp-pd/prof/details/ page.cfm Lang $=$ E\&Geo1 $=$ CSD $\&$ Code $1=5901012 \&$ Geo $2=$ PR\&Code $2=59 \&$ Data $=$ Count $\& S$ earchText=Fernie\&SearchType=Begins\&SearchPR=01\&B1=All\&Custom $=$

Statistics Canada. (2011c). Census profile: Sparwood. Retrieved from http://www12.statcan.gc.ca/census-recensement/2011/dp-pd/prof/details/ page.cfm?Lang=E\&Geo1=CSD\&Code $1=5901006 \&$ Geo2 $=$ PR \&Code $2=59 \&$ Data $=$ Count $\& S$ earchText=Sparwood \&SearchType=Begins\&SearchPR=59\&B1=All\&Custom $=\&$ TABID $=1$

Statistics Canada. (2011d). National household survey: NHS Elkford. Retrieved from http://www12.statcan.gc.ca/nhs-enm/2011/dp-pd/prof/details/ page.cfm?Lang=E\&Geo1=CSD\&Code1 $=5901003 \&$ Data $=$ Count\&SearchText=elkford \&Sea rchType=Begins $\&$ SearchPR=01\&A1=All\&B1=All\&Custom $=\& T A B I D=1$

Statistics Canada. (2011e). National household survey: NHS Fernie. Retrieved from http://www12.statcan.gc.ca/nhs-enm/2011/dp-pd/prof/details/ page.cfm?Lang $=$ E\&Geo1 $=$ CSD $\&$ Code $1=5901012 \&$ Data $=$ Count $\&$ SearchText $=$ fernie $\&$ Sear chType=Begins \&SearchPR=01\&A1=All\&B1=All\&Custom $=\&$ TABID $=1$

Statistics Canada (2011f). National household survey: NHS Sparwood. Retrieved from http://www12.statcan.gc.ca/nhs-enm/2011/dp-pd/prof/details/ page.cfm?Lang $=$ E\&Geo1 $=$ CSD\&Code $1=5901006 \&$ Data $=$ Count $\&$ SearchText $=$ sparwood $\&$ SearchType=Begins \&SearchPR=01\&A1=All\&B1=All\&Custom $=\&$ TABID $=1$

Statistics Canada (2011g). Survey of labour and income dynamics. Retrieved from http://www23.statcan.gc.ca/imdb/p2SV.pl?Function=getSurvey\&SDDS=3889

Teck Coal Limited. (2015, September 3). Re: Mine sites. Retrieved from http://www.teck.com/Generic.aspx?PAGE=Teck+Site\%2fDiversified+Mining+Pages\%2fC oal+Pages\%2fCoal+Mountain\&portalName=tc

Watson, G. (2001). Rural child care in Canada: Directions for farm safety [Rural Child Care Report]. Winnipeg, MB: Canadian Agricultural Safety Association. Retrieved from http://casa-acsa.ca/fr/node/4510

Williams, C. (2008). Work-life balance of shift workers (Statistics Canada Catalogue no. 75-001X). Ottawa. Retrieved from http://www.statcan.gc.ca/pub/75-001-x/2008108/pdf/10677eng.pdf 